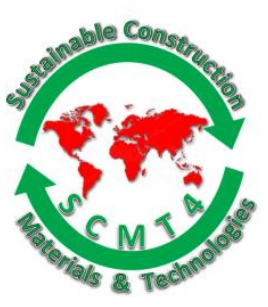

SCMT4

Las Vegas, USA, August 7-11, 2016

\title{
Salient Parameters Influencing the Strength Properties of Cement- Less Wastepaper Based Lightweight Block
}

\author{
Oriyomi M Okeyinka ${ }^{1 \mathrm{a}}$, David A Oloke ${ }^{1 \mathrm{~b}}$, and Jamal M Khatib ${ }^{1 \mathrm{c}}$ \\ ${ }^{1}$ School of Architecture and the Built Environment, Faculty of Science and Engineering, University of \\ Wolverhampton, City Campus, Wolverhampton, West Midlands WV1 1LY, United Kingdom. \\ ${ }^{1 a}$ Email: $\langle O . M . O k e y i n k a @ w l v . a c . u k\rangle,{ }^{1 b}$ Email: $\langle D . A . O l o k e @ w l v . a c . u k\rangle$, \\ ${ }^{1 c}$ Email: $<j . m . k h a t i b @ w l v . a c . u k>$.
}

\begin{abstract}
The continuous suggestions of using environmental friendly construction materials as a means of achieving sustainability in the construction industry has led to various investigation exploring the recycled use of wastes for the production of building materials. Considering the level of research efforts to date, this investigation was conducted to study the effect of salient parameters, which includes; particle size of wastepaper aggregate (WA), curing methods/temperature, and crushing orientation on the compressive strength of cement-less wastepaper lightweight block (CWLB). The laboratory experimentation involved the systematic molding of 50mmx50mmx50mm CWLB specimens and testing their compressive strength at 28 days of curing in ambient laboratory temperature $\left(20^{\circ} \mathrm{C}\right)$. The test results show that the compressive strength of CWLB vary with particle size of WA, specimens molded from finer WA particles exhibit about $50 \%$ higher average compressive strength (for all the mixes tested) compared to those molded from the coarser particle sizes. Curing at varying temperature has an insignificant effect on the compressive strength of CWLB; at $\left(20^{\circ} \mathrm{C}\right)$ ambient laboratory temperature the specimen displayed $1.7 \%$ higher compressive Strength at 28 days curing age compared to those cured at $\left(30^{\circ} \mathrm{C}\right)$ oven temperature. Specimen crushed on the as cast (top) face showed $101 \%$ higher compressive strength and ductile mode of failure compared to the lower strength and brittle mode of failure observed on the as cast side. These findings indicates that; CWLB is suitable for use at both hot and cold temperate regions, it exhibits varying strength at different loading orientations, it displays properties different from wood in terms of loading orientation and the WA particle size play a major role in the strength development of CWLB. Thus, to efficiently produce and make specification for CWLB, adequate consideration should be given to the parameter studied. Future work will study the effect of other parameters including; curing age, water content, binder content, and water/binder ratio.
\end{abstract}

\section{INTRODUCTION}

The rapid growth of civil engineering construction has led to increasing demand for aggregates and other natural resources required for the production of building material. One of the major notable environmental impacts associated with the construction industry is the high consumption of natural resources. The raw materials (e.g. aggregate and cement) utilized in the production of concrete are either obtained or produced from naturally occurring minerals. 
According to literature, the production of every 1 ton of cement requires about 1.7 tons of non-fuel raw materials out of which limestone account for $85 \%$, while other raw materials (e.g. Clay and shale) accounts for the remaining 15\% (Oss and Padovani, 2003). The building industry requires about six to seven more tonnes of sand and gravel, for each tonnes of cement used in construction, (United States Geological Survey (USGS), 2013).Globally, sand and gravel accounts for 68 to $85 \%$ of about 59 billion tonnes of material mined every year (Seinberger et al, 2010; Krausmann et al, 2009). The 25.9 to 29.6 billion estimated world use of aggregate for concrete in year 2012 alone was estimated to represent enough concrete to build a 27 meter high by 27 meter wide wall around the equator (UNEP Global Environmental Alert Services (UNEP GEAS), 2014). The world over 40 billion tonnes annual aggregate consumption was estimated to be about $100 \%$ more than the yearly aggregate renewal by all rivers of the world (UNEP GEAS, 2014).

The cummulative effect of these consumption is gradually making the creation of the built environment to become a threat to the natural eco -system. As an evidence, the natural resources based of the world has been reported to be in severe state of over-exploitation and depletion (Giljum et al, 2009). It is therefore paramount to investigate means of achieving sustainability in the production of building materials in the construction industry.

To effectively offset the impact, there has been a continuous suggestion of exploiting environmentally friendly construction materials. Mehta (2002) recommended two sets of approaches viz; the practice of industrial ecology in which the waste by product from one industry is utilized as a major raw material in another industry, and secondly, the reduction in the impact of unwanted by-products through a minimization of material consumption. Other suggestions includes: reducing the environmental impact of materials used in construction and targeting responsible sourcing of construction products (Strategic for Sustainable Construction, 2008), use of environmentally-friendly construction materials, innovative manufacturing processes and design of innovative products using recycled material (European Union(EU) Commission, 2013).

Following these suggestions, several researches had been conducted to explore the potential of developing building materials from various types of wastes including wastepaper. Building materials such as: fibre cement board (Asorie et al, 2011), lightweight block (Okeyinka et al, 2015a; Modry, 2001, Fuller et al, 2006), low density board (Esmeradal, 2000), papercrete (Fuller et al, 2006), plastering mortar (Acui et al, 2014), have been produced from wastepaper. However, extensive literature review has shown that, building material produced from waste paper suffers high water absorption (Akinwumi et al, (2014); Tizmany, (2006), and Acui et al, (2014)), thickness swelling and low strength with increasing paper fibre content. This drawback of strength reduction arise due to the corresponding water content increment that occurs in the mix with increasing waste paper content (Abdul Ghani and Shukeri, 2008). This indicates the contradiction that exists between the hygroscopic properties of paper fibre and the moderate water requirement for cement hydration, which means that the high water cement ratio resulting from increasing paper content lowers the strength of the building material concerned. The utilization of considerable quantity of cement to improve the strength properties offset the environmental friendliness of building materials made from wastepaper.

The development of cement-less wastepaper based lightweight block (CWLB) was another important step towards the production of eco-friendly building materials. This block which was designed to be used for non-load bearing/ non-structural application was developed without the use of hydraulic cement. It constituents are majorly waste materials, which includes; postconsumer waste paper, waste additive (obtained as industrial waste by-product), and lesser quantities of sand, water and admixture. The details of the exploratory study involved in development of its mixture proportioning process was reported and published (Okeyinka et al, 2015a; Okeyinka et al, 2015b). 
Considering the level of recycled waste content in the CWLB, it development and production will not only reduce the consumption of natural resources in building construction but will also offset the utilization of cement whose production is associated with environmental impacts such as GHG emission, high raw material consumption and high energy consumption. Being a relatively new material, many of the characteristics of CWLB are yet to be studied and understood. For instance, unlike concrete and papercrete which form paste in the fresh state due the inclusion of hydraulic cement in their constituents, CWLB exhibits fibrous form in the fresh state (Okeyinka et al, 2015b) as it was made from majorly inert/unreactive materials. Thus, adequate understandings of the salient parameters that affect its strength properties are important for processing and product optimization. This study was therefore conducted to determine the effect of parameters which includes; curing method, wastepaper aggregate (WA) particle sizes and crushing orientation on the compressive strength of CWLB.

\section{MATERIALS AND METHODS}

The materials used in this experimentation includes wastepaper aggregate (WA), sand (fine aggregate), waste additive (binder), clay (admixture) and water. The wastepaper aggregate (WA) was produced through a systematically processing of post-consumer wastepaper (Okeyinka et al, 2015) specifically old Newsprint. The WA used was divided into two different types (viz; type (A) and type (B)) in terms of their particle granulation. The type (A) WA exhibited particle size/granulation ranging from $4 \mathrm{~mm}-0.125 \mathrm{~mm}$ (Fig 1). The type (B) WA has particle sizes ranging from $1 \mathrm{~mm}-0.063 \mathrm{~mm}$ (Fig 1) and it was produced by subjecting the type (A) WA (with $4 \mathrm{~mm}-0.125 \mathrm{~mm}$ particle size) to grinding in a ball milling machine at a rotating speed of 360rpm for 15 minutes.

\section{Mixture Proportioning and Batching of Constituent Materials}

The choice of mixes selected for the production of test specimen in this experimentation was based on the exploratory study conducted to develop the mixture proportioning process for the CWLB under study as published in (Okeyinka et al, 2015a; Okeyinka et al, 2015b). Five (5) mixes containing varying sand contents ranging from $36 \%$ (by weight of WA) to 52\% (by weight of WA) but constant; binder quantity ( $20 \%$ by weight of WA), admixture quantity ( $5 \%$ by weight of WA) and water/ binder ratio (3.75) were found to possess desirable properties that satisfies the criterial for the selection of efficient mix composition in terms of dimensional stability and density (Okeyinka et al, 2015b) as specified by the BS EN 772-2 (2013) and BS EN 2028-1, (1975) for masonry block to be used for wall construction. The compressive strength of the selected mixes is expected to be improved upon based on the findings from the study of salient parameters. In order to limit the number of runs and obtain only the factor effects, each of the parameter studied were tested against the compressive strength separately. Also, other parameters of these mixes which includes; water/binder ratio, optimum water content, curing, optimum amount of compacting pressure etc., will be further optimized based on the outcome of future investigation of the effect of different salient parameters on the compressive strength of the CWLB specimen.
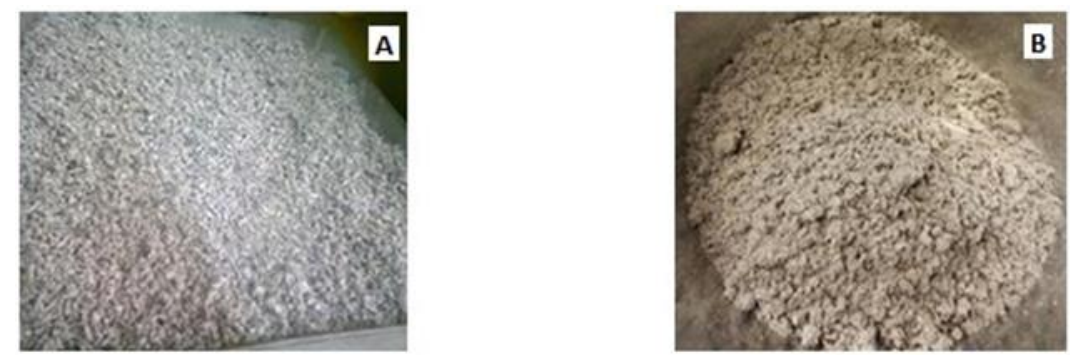

Figure 1. Type (A) and Type (B) WA with varying particle size/granulation 
Considering the disparity between the physical properties of the wastepaper aggregate (WA) and the fine aggregate (sand) as shown in table (2). All constituent materials used in this experimentation were measured by weight in order to ensure adequate proportioning. Materials which include; sand, binder, water and admixture were measured relative to the quantity of WA in the mixture.

Table 2. Differences between the physical properties of wastepaper aggregate and sand (fine aggregate) (Source: Okeyinka et al, (2015b))

\begin{tabular}{|l|l|l|}
\hline \multirow{2}{*}{ Physical Properties } & Materials & \multicolumn{2}{|l|}{ Sand } \\
\cline { 2 - 3 } & WA & 2.63 \\
\hline Specific gravity & 0.661 & $1.428 \mathrm{~kg} / \mathrm{l}$ \\
\hline Loose Bulk density & $0.096 \mathrm{~kg} / \mathrm{l}$ & $4 \mathrm{~mm}-0.063 \mathrm{~mm}$ \\
\hline Particle sizes & $4 \mathrm{~mm}-0.125 \mathrm{~mm}$ & \\
\hline
\end{tabular}

\section{Manufacture of Test Specimen}

After mixing the constituent materials in a portable mortar mixer, a predetermined quantity of the mixture was weighed and filled into the $50 \mathrm{~mm} \times 50 \mathrm{~mm} \times 150 \mathrm{~mm}$ cubic mould to produce the cube block specimen (Fig 3). A 10 tonnes capacity manual hydraulic press with a pressure measuring gauge and piston (Fig 4) was used to compress the mixture against the other end of the mould to form the $50 \mathrm{mmx} 50 \mathrm{~mm} \times 50 \mathrm{~mm}$ cube block specimen. The $50 \mathrm{~mm} \times 50 \mathrm{~mm} \times 150 \mathrm{~mm}$ mould was initially utilised to accommodate the fibrous and the voluminous nature of the mixture. The amount of compacting force employed in compressing the mixture was 2.5 metric tons which is equivalent to a compacting pressure of $9.807 \mathrm{MPa}$.This process was repeated for all specimens produced from each of the mixes.

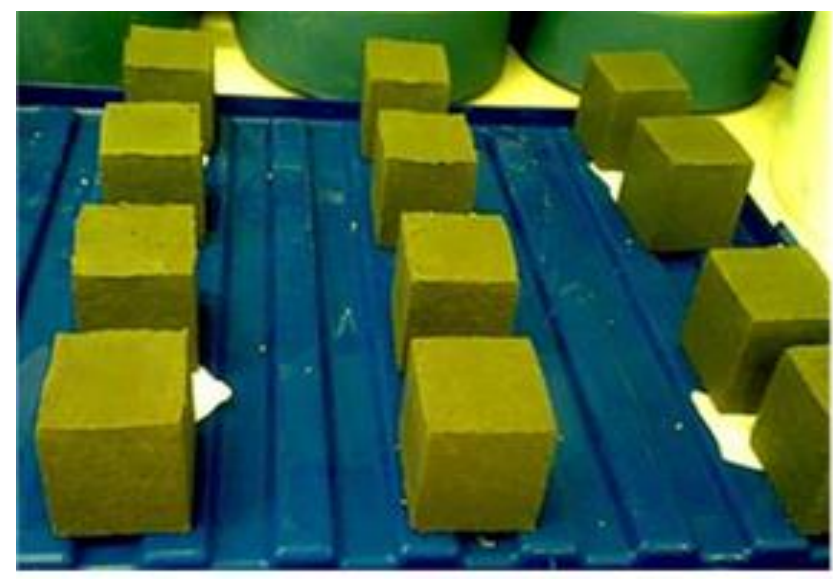

Figure 3. 50mm X 50mm x $50 \mathrm{~mm}$ CWLB System

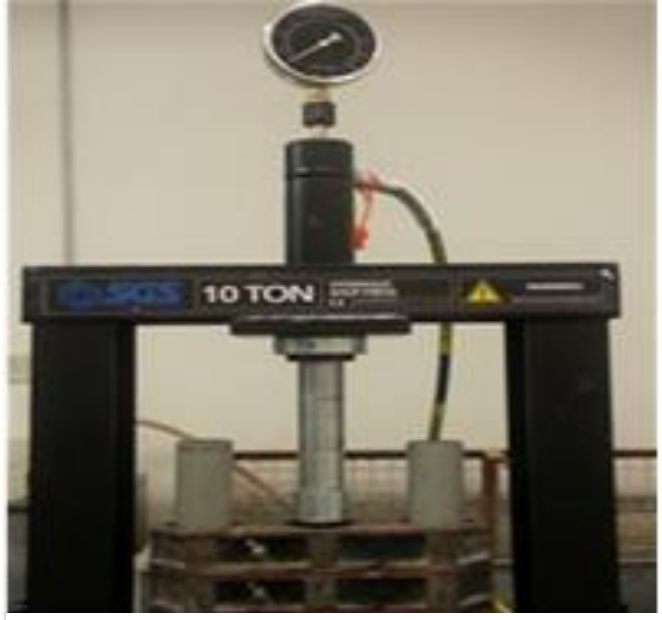

Figure 4. 10 tonnes capacity manual hydraulic press with a pressure measuring gauge and piston 


\section{Preparation of Specimen for the study of salient parameters}

The details of the mixes and different additional preparation for the production of specimen use in testing the salient parameters under study are explained in this section.

\section{Details of Specimen for testing the effect of curing method/Temperature.}

The specimen used for exploring the effect of two different curing methods on the compressive strength of the CWLB specimen were made from mixes 1 and 5 as detailed in table 2. The two curing methods/temperature investigated includes; ambient curing $\left(20^{\circ} \mathrm{C}\right)$ and oven curing $\left(30^{\circ} \mathrm{C}\right)$. The ambient cured specimen were kept in room condition at $20^{\circ} \mathrm{C}$ temperature till the 28 day testing age, while the oven cured specimen were subjected to curing in the oven at $30^{\circ} \mathrm{C}$ for 28 days and were taken out to cool down in room temperature before testing. The oven cured temperature of $30^{\circ} \mathrm{C}$ was adopted to replicate the average temperature condition that the specimen may be subjected to in a hot/warm temperate region. Investigating this parameter is expected to help in determining the suitability of using the CWLB in hot/warm environment.

Table 3. Mixture proportioning of specimen for testing the effect of curing method and crushing orientation.

\begin{tabular}{|c|c|c|c|c|c|c|c|c|}
\hline \multirow[b]{2}{*}{ 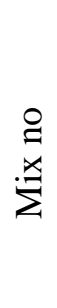 } & \multirow[b]{2}{*}{ 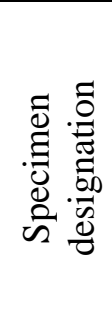 } & \multicolumn{2}{|c|}{ Aggregates } & \multirow{2}{*}{ 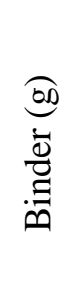 } & \multirow{2}{*}{ 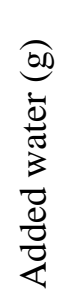 } & \multirow{2}{*}{ 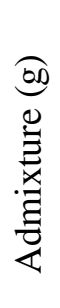 } & \multirow{2}{*}{ 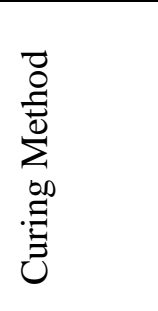 } & \multirow{2}{*}{ 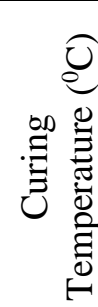 } \\
\hline & & 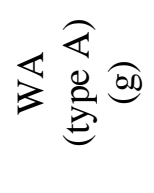 & 胥 & & & & & \\
\hline \multirow[t]{2}{*}{1} & $\mathrm{c}$ & 300 & 156 & 60 & 225 & 15 & Ambient & 20 \\
\hline & $\mathrm{d}$ & 300 & 156 & 60 & 225 & 15 & Oven & 30 \\
\hline \multirow[t]{2}{*}{5} & $\mathrm{c}$ & 300 & 108 & 60 & 225 & 15 & Ambient & 20 \\
\hline & $\mathrm{d}$ & 300 & 108 & 60 & 225 & 15 & Oven & 30 \\
\hline
\end{tabular}

\section{Details of Specimen for testing the Effect of particle size}

The specimen used to study this parameter were produced from mixes 1-5 (table 3) using the different types of the wastepaper aggregates viz:

- The Type A:- The coarser WA with particle size range of $4 \mathrm{~mm}-0.125 \mathrm{~mm}$ (fig 1)

- $\quad$ The type B: - The finer WA with particle size range of $1 \mathrm{~mm}-0.063 \mathrm{~mm}$ (fig 2).

Given the effect of WA particle size on water requirement of the CWLB specimen as reported in (Okeyinka et al 2015b), the water to binder ratios adopted for the mixes made from type (A) WA and type (B) WA were; 10 and 3.75 respectively. After moulding and demoulding, the specimens were cured in ambient laboratory condition for 28days. 
Table 4. Mixture proportioning of specimen for testing the effect of WA particle size

\begin{tabular}{|c|c|c|c|c|c|c|}
\hline \multirow{3}{*}{$\begin{array}{l}\stackrel{̊}{\Xi} \\
\stackrel{x}{\Sigma}\end{array}$} & \multirow{3}{*}{ 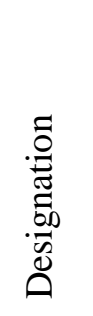 } & \multicolumn{3}{|c|}{ Aggregates } & \multirow{3}{*}{ 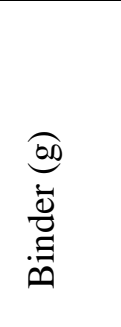 } & \multirow{3}{*}{ 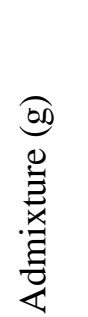 } \\
\hline & & \multicolumn{2}{|c|}{$\begin{array}{c}\text { Wastepaper Aggregate(WA) } \\
(\mathrm{g})\end{array}$} & \multirow[t]{2}{*}{$\begin{array}{l}\text { Sand } \\
(\mathrm{g})\end{array}$} & & \\
\hline & & Type A & Type B & & & \\
\hline \multirow[t]{2}{*}{1} & $\mathrm{a}$ & 300 & - & \multirow[t]{2}{*}{156} & \multirow[t]{2}{*}{60} & \multirow[t]{2}{*}{15} \\
\hline & $\mathrm{b}$ & - & 300 & & & \\
\hline \multirow[t]{2}{*}{2} & $\mathrm{a}$ & 300 & - & \multirow[t]{2}{*}{144} & \multirow[t]{2}{*}{60} & \multirow[t]{2}{*}{15} \\
\hline & $\mathrm{b}$ & - & 300 & & & \\
\hline \multirow[t]{2}{*}{3} & $\mathrm{a}$ & 300 & - & \multirow[t]{2}{*}{132} & \multirow[t]{2}{*}{60} & \multirow[t]{2}{*}{15} \\
\hline & $\mathrm{b}$ & - & 300 & & & \\
\hline \multirow[t]{2}{*}{4} & $\mathrm{a}$ & 300 & - & \multirow[t]{2}{*}{120} & \multirow[t]{2}{*}{60} & \multirow[t]{2}{*}{15} \\
\hline & $\mathrm{b}$ & - & 300 & & & \\
\hline \multirow[t]{2}{*}{5} & $\mathrm{a}$ & 300 & - & \multirow[t]{2}{*}{108} & \multirow[t]{2}{*}{60} & \multirow[t]{2}{*}{15} \\
\hline & $\mathrm{b}$ & - & 300 & & & \\
\hline
\end{tabular}

Details of Specimen for testing the Effect of Crushing Orientation. To determine the effect of crushing orientation on the compressive strength of the CWLB, cube block specimen of sizes $50 \mathrm{~mm} \times 50 \mathrm{~mm} \times 50 \mathrm{~mm}$ were moulded from mixes 1 and 2 (table 3 ) and were subjected to curing in ambient laboratory condition for 28 days prior to compressive strength test. Two different crushing orientation which includes the as cast face (Top Face) and the as cast side (side face) were investigated for the specimen produced from each of the mixes.

Testing of Specimen. Considering the intrinsic importance of compressive strength in the design of structures (Neville, 1995) and its recommendation as an important property for consideration in the development of mixture proportioning process (BS 5328-2:1997), the salient parameters under study were tested against the compressive strength of the CWLB specimen. Other properties of the block which includes; water absorption, fire resistance, dimensional check, density, shrinkage and flexural strength will be investigated in (future experimentation) after the optimisation of the mixes.

Compressive Strength Test. At 28days curing age, the CWLB specimens were subjected to compressive strength test in a $2500 \mathrm{KN}$ capacity compression testing machine at a loading rate of $2400 \mathrm{~N} / \mathrm{S}$. The 28 days curing age was adopted for all the salient parameters investigated, in order to simplify the process and to minimize the material consumption. 


\section{RESULT AND DISCUSSIONS}

Effect of Curing Method on the Compressive Strength of CWLB. As presented in table 5 below, the difference between mixture $1 \mathrm{c}$ and $1 \mathrm{~d}$ is the curing method/temperature at $20^{\circ} \mathrm{C}$ and $30^{\circ} \mathrm{C}$ respectively. The specimen 1c cured at ambient laboratory condition displayed 1.7\% higher compressive Strength at 28days curing age compared to specimen 1d. A similar trend was also observed for the specimen $2 \mathrm{c}$ and $2 \mathrm{~d}$. Considering the negligible difference between the compressive strength of the specimen subjected to the two different curing methods, it is clear that curing at higher or lower temperature produces little or no significant effect on the development of compressive strength of CWLB. This indicates the possibility of utilizing the CWLB block at both hot and cold temperate regions.

Table 5. Effect of curing method/Temperature on compressive strength of CWLB

\begin{tabular}{|c|c|c|c|c|c|}
\hline Mix no & $\begin{array}{c}\text { Parameter } \\
\text { Designation }\end{array}$ & $\begin{array}{c}\text { Temperature } \\
\left({ }^{\circ} \mathrm{C}\right)\end{array}$ & Curing method & $\begin{array}{c}\text { Average } \\
\text { Compressive } \\
\text { Strength (MPa) }\end{array}$ & $\begin{array}{c}\text { Standard } \\
\text { deviation }\end{array}$ \\
\hline \multirow{2}{*}{1} & $\mathrm{c}$ & 20 & Ambient & 0.69 & 0.07 \\
\cline { 2 - 6 } & $\mathrm{d}$ & 30 & Oven & 0.67 & 0.05 \\
\hline \multirow{2}{*}{5} & $\mathrm{c}$ & 20 & Ambient & 0.54 & 0.03 \\
\cline { 2 - 6 } & $\mathrm{d}$ & 30 & Oven & 0.51 & 0.05 \\
\hline
\end{tabular}

Effect of Crushing Orientation on the Compressive Strength of CWLB. The compressive strength displayed by the specimen subjected to crushing on the as-cast side face $\left(1 \mathrm{C}_{S}\right)$ and the as cast top face $\left(1 \mathrm{C}_{\mathrm{T}}\right)$ are presented in table 6 below. The difference between specimen $1 \mathrm{C}_{\mathrm{S}}$ and $1 \mathrm{C}_{\mathrm{T}}$ is the crushing orientation at the side-face and top-face respectively. The specimen $1 \mathrm{C}_{\mathrm{T}}$ crushed on the top-face displayed approximately $101 \%$ higher compressive strength compared to specimen $1 \mathrm{C}_{\mathrm{s}}$ that was crushed on the as cast side. A ductile mode of failure was also observed in specimen crushed on the top-face while a brittle mode of failure was observed in specimen crushed on side-face. The physical observation of the specimen cross section shows that, similar to the mechanism of densification of biomass (Kaliyan and Morey 2009), the wastepaper fibres rearranged themselves in a direction perpendicular to direction of the applied pressure during the process of compaction under the hydraulic press. This indicates that the CWLB block specimen are stronger in the direction perpendicular to their fibre orientation and are weaker in the direction parallel to their fibre orientation. A comparison of this characteristics with wood indicate that the CWLB exhibit properties different from wood in terms of loading orientation given the fact that wood are stronger in the direction of orientation of its fibre and are weaker in the direction perpendicular to its fibre orientation (Thelanderson and Larsen, 2003).

Table 6. Effect of crushing orientation on compressive strength of CWLB

\begin{tabular}{|c|c|c|c|c|}
\hline Mix no & $\begin{array}{c}\text { Parameter } \\
\text { Designation }\end{array}$ & Crushing Orientation & $\begin{array}{c}\text { Average Compressive } \\
\text { Strength (MPa) }\end{array}$ & $\begin{array}{c}\text { Standard } \\
\text { deviation }\end{array}$ \\
\hline \multirow{2}{*}{1} & $\mathrm{C}_{\mathrm{S}}$ & Side face & 0.69 & 0.07 \\
\cline { 2 - 5 } & $\mathrm{C}_{\mathrm{T}}$ & Top Face & 1.39 & 0.04 \\
\hline 5 & $\mathrm{C}_{\mathrm{S}}$ & Side face & 0.54 & 0.03 \\
\cline { 2 - 5 } & $\mathrm{C}_{\mathrm{T}}$ & Top Face & 1.10 & 0.04 \\
\hline
\end{tabular}




\section{Effect of Particle Size on the Compressive Strength of CWLB}

As shown in the fig (5), specimen moulded from type (B) WA (particle size range of 1mm-0.063mm) displayed higher compressive strength compared to the specimen moulded from Type (A) WA (particle size of $4 \mathrm{~mm}-0.125 \mathrm{~mm}$ ). For all the mixes tested, the finely graded WA particle sizes produced CWLB with 49.68\% higher average compressive strength compared to the CWLB specimen molded from coarsely graded WA. This was observed to be due to higher degree of compaction (as indicated by the increased density (Okeyinka et al 2015b) made possible by the finer particle size contained in the granulation of the type (B) WA. This result and observation is in agreement with the report by Tumuluru et al (2010) that medium or finely ground particles are more suitable to achieve adequately compacted specimen in the densification of fibrous materials. It was therefore deduced that similar to densified biomass, WA particle granulation plays a major role in the degree of compaction of CWLB.

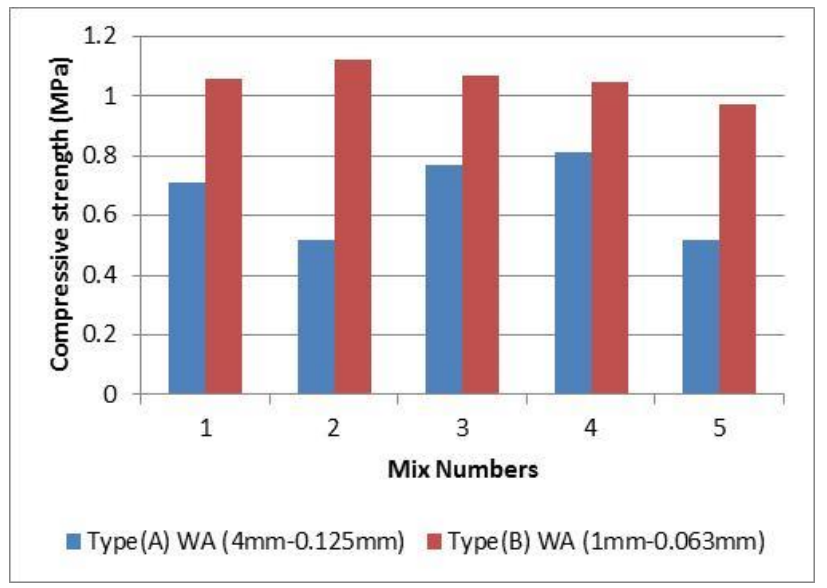

Figure 5. Influence of WA particle size/granulation on the Compressive Strength of CWLB

\section{CONCLUSION}

This paper presents the research findings of CWLB designed for non-load bearing/ non-structural application and produced from the mixture of majorly waste materials, which includes; postconsumer waste paper, waste additive (obtained as industrial waste by-product), and lesser quantities of sand, water and negligible quantity of clay as admixture. The one factor at time approach (OFAT) was adopted to investigate the effect of parameters which includes: particle size of wastepaper aggregate (WA), curing methods/temperature and crushing orientation, on the compressive strength of CWLB at 28days curing age. The effect of curing method/temperature was examined by comparing the compressive strength of by specimen subjected to $20^{\circ} \mathrm{C}$ ambient curing temperature and $30^{\circ} \mathrm{C}$ oven curing temperature for periods of 28days respectively. The effect of particle size of WA was investigated by comparing the compressive strength of CWLB specimen molded from a coarsely grained $(4 \mathrm{~mm}-0.125 \mathrm{~mm})$ WA and a finely grained $(1 \mathrm{~mm}-0.063 \mathrm{~mm}) \mathrm{WA}$. Effect of crushing orientation was studied by comparing the compressive strength of CWLB subjected to compression on the as-cast top face and on the as-cast side face respectively. The experimental results reported in this paper led to the following conclusions:

There was an insignificant difference between the compressive strengths of CWLB specimens cured at $30^{\circ} \mathrm{C}$ oven temperature and those cured at $20^{\circ} \mathrm{C}$ ambient laboratory temperature. This indicates the possibility of utilizing the CWLB block at both hot and cold temperate regions. 
CWLB exhibit varying compressive strength and mode of failure at different loading orientation. The CWLB specimen loaded and crushed on the top-face displayed approximately $101 \%$ higher compressive strength compared to those loaded and crushed on the as cast side. This indicates that the CWLB block specimen are stronger in the direction perpendicular to their fibre orientation and are weaker in the direction parallel to their fibre orientation unlike wood which are stronger in the direction of orientation of its fibre and are weaker in the direction perpendicular to its fibre orientation. A ductile mode of failure was also observed in the specimens crushed on the top-face while a brittle mode of failure was observed in the specimens crushed on side-face.

WA particle granulation plays a major role in the degree of compaction of CWLB. Finely graded (1mm$0.063 \mathrm{~mm}$ ) WA produces CWLB with $49.68 \%$ higher average compressive strength compared to the coarsely graded $(4 \mathrm{~mm}-0.125 \mathrm{~mm}) \mathrm{WA}$.

\section{REFERENCES}

Aciu, C., Iluţiu-Varvara, D.A., Cobirzan, N. and Balog, A. (2014) "Recycling of paper waste in the composition of plastering mortars". Procedia Technology, 12pp. 295-300.

Akinwumi, I.I., Olatunbosun, O.M., Olofinnade, O.M. and Awoyera, P.O. (2014) "Structural Evaluation of Lightweight Concrete Produced Using Waste Newspaper and Office Paper". Civil and Environmental Research, 6(7), pp. 160-167.

Ashori, A., Tabarsa, T. and Valizadeh, I. (2011) "Fiber reinforced cement boards made from recycled newsprint paper". Materials Science and Engineering: A, 528(25), pp. 7801-7804.

BS EN 772-1 (2011) "Methods of test for masonry units. Determination of compressive strength" British Standards Institute.

BS 5328-2 (1997) "Concrete. Methods for specifying concrete mixes” British Standards Institute.

European Environment Agency (EEA) (2013) European Topic Centre on Sustainable Consumption and Production. Available at: 〈http//:www.spc.eionet.europa.eu/theme/waste>.

Fuller,B., Fafitis,A. and Santamaria,J. (2006) "Structural Properties of a New Material Made of Waste Paper AEI 2006” Building Integration Solutions. ASCE, pp.1-16.

Giljum, S., Hinterberger, F., Bruckner, M., Burger, E., Frühmann, J., Lutter, S., Pirgmaier, E., Polzin, C., Waxwender, H. and Kernegger, L. (2009) "Overconsumption? Our use of the world's natural resources". < http://www.foe.co.uk/sites/default/files/downloads/overconsumption.pdf >.

HM Government in association with Strategic forum for Construction (2008) "STRATEGY FOR SUSTAINABLE CONSTRUCTION JUNE 2008”, United Kingdom: Department for Business, Enterprise \& Regulatory Reform. <www.berr.gov.uk>.

Kaliyan, N. and Morey, R.V. (2009) "Constitutive model for densification of corn stover and switchgrass". Biosystems engineering, 104(1), pp. 47-63.

Krausmann, F., Gingrich, S., Eisenmenger, N., Erb, K., Haberl, H. and Fischer-Kowalski, M. (2009) "Growth in global materials use, GDP and population during the 20th century". Ecological Economics, 68(10), pp. 2696-2705. 
McCaffrey, R. (2002) "Climate Change and the Cement Industry". Global Cement and Lime Magazine, (Environmental Special Issue), pp. 15-19.

Modry,S. (2001) "Use of Waste Paper as a Constituent of Concrete" Recovery and recycling of paper international symposium, Thomas Telford Publishing, United Kingdom. pp.77-80.

Neville, A.M. (1995) Properties of concrete.

Okeyinka O.M., David D.A, Khatib J. M. (2015a) "Development of Environmentally Friendly Light weight block from Waste paper” 2nd International Sustainable Buildings Symposium (ISBS 2015). , 28-30 May. The Scientific and Technological Research Council of Turkey, pp.406-416.

Okeyinka O.M., David D.A, Khatib J. M. (2015b), "Development of an eco- friendly lightweight block from post-consumer waste paper".In Press

Okino, E.Y.A., Santana, M.A.E. and de Souza, M.R. (2000) "Utilization of wastepaper to manufacture low density boards". Bioresource technology, 73(1), pp. 77-79.

Oss, H.G. and Padovani, A.C. (2003) "Cement manufacture and the environment part II: environmental challenges and opportunities". Journal of Industrial Ecology, 7(1), pp. 93-126.

Peduzzi, P. (2014) "Sand, rarer than one thinks. Environmental Development”, (11), pp. 208-218.

Steinberger, J.K., Krausmann, F. and Eisenmenger, N. (2010) "Global patterns of materials use: A socioeconomic and geophysical analysis". Ecological Economics, 69(5), pp. 1148-1158.

Thelandersson, S. and Larsen, H.J. (2003) Timber engineering. Chapter 2 pg. 15, John Wiley \& Sons.

USGS, 2013. "Sand and gravel (construction) statistics", in: Kelly, T.D., Matos, G.R., (Eds.), Historical statistics for mineral and material commodities in the United States. U.S. Geological Survey Data Series 140, Reston.

UNEP GEAS, (2014), "Sand rarer than one thinks" Thematic focus: Ecosystem management, Environmental governance, Resource efficiency. UNEP Global Environmental Alert Services (GEAS). 